\title{
I solation and characterization of bacteria from canine respiratory diseases in and around Hyderabad city, Andhra Pradesh, India
}

\author{
S. Ayodhya, D. S. Tirumala Rao, Y. Narsimha Reddy, N. Syam Sundar and V. Girish Kumar \\ Department of Clinical Veterinary Medicine \\ College of Veterinary Science, Rajendranagar, Sri Venkateswara Veterinary University, \\ Hyderabad, Andhra Pradesh, India \\ Corresponding author: S. Ayodhya, email: sayodhya 6@yahoo.com \\ Received: 23-01-2013, Revised: 05-03-2013, Accepted: 06-03-2013, Published online: 18-06-2013
}

How to cite this article: Ayodhya S, Tirumala Rao DS, Narsimha Reddy Y, Syam Sundar N and Girish Kumar V (2013) Isolation and characterization of bacteria from canine respiratory diseases in and around Hyderabad city, Andhra Pradesh, India, Vet World 6(9): 601-604, doi: 10.5455/vetworld.2013.601-604

\begin{abstract}
Aim: To identify the organisms causing respiratory diseases in dogs that belongs to areas in and around Hyderabad city.

Materials and Methods: Nasal samples were collected using sterile swabs from the canine clinical cases that were presented with the history of respiratory diseases at the University administered Veterinary Hospital, Bhoiguda, Secunderabad and Campus Veterinary Hospital, College of Veterinary Science, Rajendranagar, Hyderabad over a period of 26 months i.e., from October 2008 to November 2010. Clinical signs included coughing, nasal discharge, sneezing, difficulty in breathing, fever, loss of appetite and lethargic behavior. Nasal swabs were immediately transferred, aseptically, into a nutrient broth and were subjected to various cultural tests and microscopic examination.
\end{abstract}

Results: Out of 90 nasal samples, different species of bacteria were isolated. Results from our bacterial culture, microscopic and biochemical studies of the nasal discharges collected from dogs suffering with respiratory diseases revealed various bacteria such as E. coli, Klebsiella spp, Streptococci spp. Staphylococci and mixed infections.

Conclusion: This study revealed that the bacteria such as E. coli, Klebsiella spp, Streptococci spp. Staphylococci and mixed infections are the common causative agents that lead to respiratory diseases in dogs belonging to areas in and around Hyderabad city.

Keywords: bacteriology, characterization, cultural tests, dogs, isolation, respiratory diseases

\section{I ntroduction}

Rearing of dogs and other pet animals has become increasingly popular in modern society. In this context it is important to note that respiratory diseases pose a major health problem in dogs and other pet animals worldwide. This is because clinical manifestations associated with canine respiratory diseases appear suddenly. Sometimes they may be chronic, refractory and resistant to commonly employed antibiotics [1]. There is a need to formulate procedures for the clinical management of respiratory diseases in dogs in order to achieve quick therapeutic response and also to alleviate pain and suffering. Respiratory medicine is an advanced branch of veterinary medicine where the growth and development has been far below the satisfactory level both in small and large animal practice. Respiratory diseases are associated with various etiological agents such as bacterial, viral, parasitic and others [1-4]. Among these agents, respiratory disease due to bacterial etiology is common in dogs [1-4]. Respiratory disease is a challenging condition to diagnose [5] and to treat as patients can exhibit a wide range of clinical presentations ranging from dyspnoea, costal or abdominal respiration, cough,

This article is an open access article licensed under the terms of the Creative Commons Attribution License (http://creativecommons. org/licenses/by/2.0) which permits unrestricted use, distribution and reproduction in any medium, provided the work is properly cited. nasal discharge and congestion, edema, consolidation of lungs, lethargy, weight loss and ultimately fatal syndrome. Bronchoalveolar lavage fluid is the best material for bacteriological and cytological examinations in case of respiratory infections [6-11]. Bacteria involved in respiratory infections in dogs and cats are usually Escherichia coli, Klesiella spp., Streptococcus spp. and Staphylococcus spp. strains [1,3,12,13,14]. Infectious diseases of the respiratory tract caused by Staphylococcus spp. result in severe conditions and sometimes become fatal in pups. Bordetella bronchiseptica [10,15-20] and Pseudomonas spp. were also noticed in samples collected from respiratory infections [6]. Some canine cases of bacterial pneumonia from which transtracheal aspiration samples were obtained revealed the presence of Mycoplasma spp. and aerobic bacteria upon culture [12].

The objectives of this study were to study the occurrence and to classify the severity of respiratory disease based on clinical picture among the dogs in and around Hyderabad city. Furthermore, our goal was also to isolate the organisms and evaluate the antibiogram of the isolates in order to establish the identity of the etiological agent.

\section{Materials and Methods}

Based on respiratory sample analysis and severity of symptoms, $90 \mathrm{dogs}$ were selected for the study, which included dogs diagnosed for mild, moderate and 


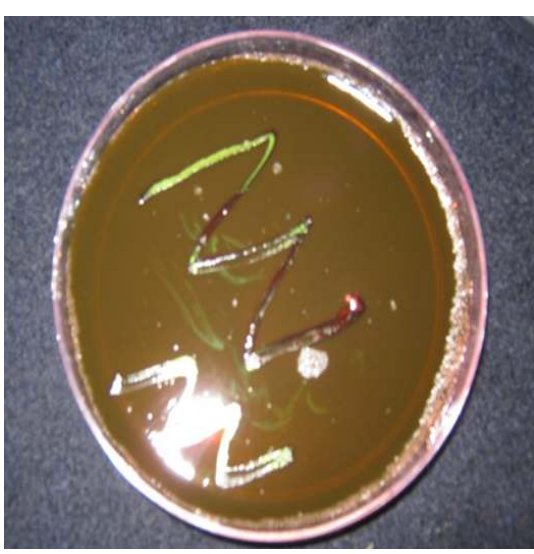

Figure-1. E. coli colonies (black) with metallic sheen appearance on EMB agar

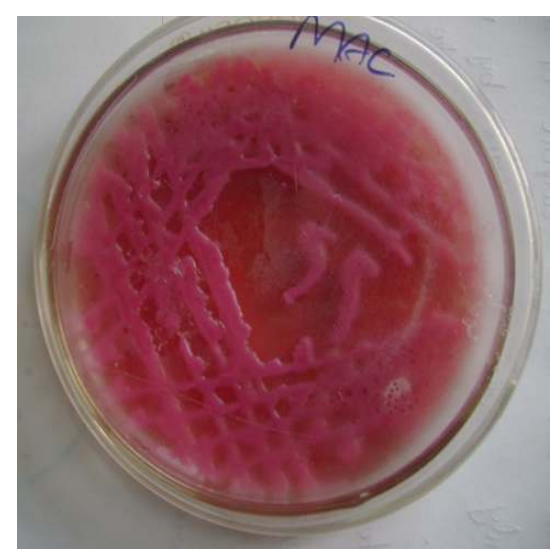

Figure-2. Pink mucoid colonies of Klebsiella spp. on MacConkey agar

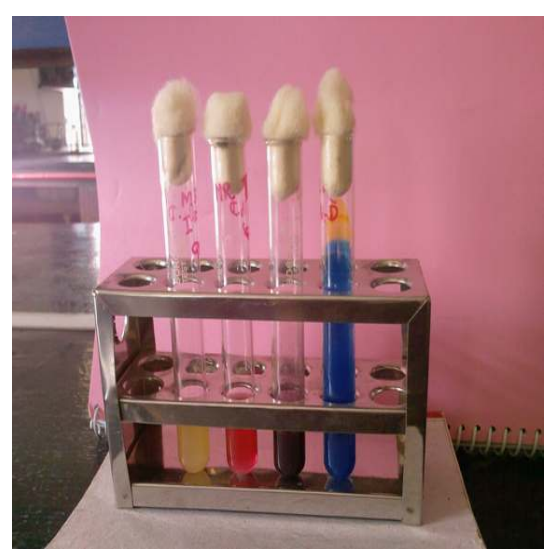

Figure-3. Test tubes showing biochemical tests

Table-1. Microbial findings in dogs with respiratory diseases

\begin{tabular}{|c|c|c|c|c|c|c|c|}
\hline \multirow[t]{2}{*}{ Sr. No. } & \multirow[t]{2}{*}{ Microorganisms } & \multicolumn{2}{|c|}{ Mild $(n=30)$} & \multicolumn{2}{|c|}{ Moderate $(n=30)$} & \multicolumn{2}{|c|}{ Severe $(n=30)$} \\
\hline & & No. of Animals & $\%$ & No. of Animals & $\%$ & No. of Animals & $\%$ \\
\hline 1 & E. colispp. & 19 & 63.33 & 9 & 30.00 & 2 & 6.67 \\
\hline 2 & Klebsiella spp. & 9 & 30.00 & 10 & 33.33 & 1 & 3.33 \\
\hline 3 & Streptococcispp. & 0 & 0 & 9 & 30.00 & 14 & 46.67 \\
\hline 4 & Staphylococci spp. & 0 & 0 & 0 & 0 & 12 & 40.00 \\
\hline \multirow[t]{2}{*}{6} & Mixed infections & 2 & 6.67 & 2 & 6.67 & 1 & 3.33 \\
\hline & Total & 30 & 100 & 30 & 100 & 30 & 100 \\
\hline
\end{tabular}

severe respiratory infections with 30 cases in each group. Dogs classified as having milder infections showed symptoms such as dry cough, watery nasal discharge but continued to eat and were alert and active. Dogs classified as having moderate infections showed symptoms like moderate dry or moist cough, moderate amounts of mucous discharge from the nostrils, mild dyspnoea, inappetence, mild fever $(102.29 \pm 0.055)$, and were less alert and less active. Dogs classified as having severe infections showed symptoms like severe dry or moist cough, severe mucopurulant nasal discharges, severe dyspnoea, dyspepsia, high fever (104.45 \pm 0.056$)$, dull and inactive. Samples were collected from dogs with the history of respiratory diseases presented at the University administered Veterinary Hospital, Bhoiguda, Secunderabad and Campus Veterinary Hospital, College of Veterinary Science, Rajendranagar, Hyderabad over a period of 26 months i.e., from October 2008 to November 2010. Immediately after collection, sterile nutrient broth was added to each sample and incubated at $37^{\circ} \mathrm{C}$ overnight. These samples were inoculated by streaking method on blood agar, MacConkey agar and Nutrient agar. The inoculated media were incubated, both under aerobic and anaerobic conditions, at $37^{\circ} \mathrm{C}$ and examined after every 12 hours until 48 hours post inoculation for the presence of any growth. Growth characteristics of the isolates were recorded. The cultures were purified by subculturing and were refrigerated for further studies. The bacteria isolated both aerobically and anaerobically from respiratory diseases showed the characteristic colony, and were gram stained and confirmed by standard biochemical tests such as catalase test, oxidase test, indole test, methyl-red test, voges-proskauer test, citrate utilization test (IMViC) and sugar fermentation tests as per the procedures detailed by Buxton and Fraser [21]. Each isolate was characterized on the basis of staining behavior, size, motility, cultural and biochemical tests.

\section{Results}

Cultural studies of samples revealed various types of bacteria in mild cases, viz., E. coli $(63.33 \%)$, Klebsiella spp. (30\%) and mixed infections (E. coli and Klebsiella spp.) (6.67\%) with corresponding 19,9 and 2 dogs (out of 30 samples), respectively. Similarly, in case of moderate respiratory diseases, samples revealed various bacteria viz., E. coli (30\%), Klebsiella spp. (33.33\%), Streptococci spp. (30\%) and mixed infections (Klebsiella spp. Streptococci spp.) (6.67\%) with corresponding 9, 10, 9 and 2 dogs (out of 30 samples), respectively. In case of severe respiratory diseases, samples revealed various bacteria viz., E. coli (6.67\%), Klebsiella spp. (3.33\%), Streptococci spp. (46.67\%), Staphylococci spp. (40\%) and mixed infection (E. coli and Staphylococci spp.) (3.33\%) with corresponding 2, 1, 14, 12 and 1 dogs (out of 30 samples), respectively.

\section{Discussion}

Our cultural studies revealed the prevalence of $E$. coli, Klebsiella spp. and mixed infections in the mild form of respiratory diseases. Similarly the moderate form of respiratory diseases revealed the prevalence of E. coli, Klebsiella spp., Streptococci spp. and mixed infection. In case of severe respiratory diseases, we observed the prevalence of E. coli, Klebsiella spp., Streptococci spp., Staphylococci spp. and mixed infection. This finding is in close agreement to earlier work carried out by Adaszek et al [1] which demon- 
strated that the isolated bacteria in canine respiratory infections were usually E. coli, Klebsiella spp. and Staphylococcus spp. strains. These findings are also well supported by the results of Angus et al. [6] who isolated the bacteria from 116 out of 264 samples (44\% positive samples) and identified 203 types of bacterial species. Most of the samples (57\%) from which bacteria could be isolated contained a single species, whereas $43 \%$ yielded cultures of mixed species. E. coli was isolated most commonly $(45.7 \%)$, followed by members of the genus Pasteurella (22.4\%), obligate anaerobes (21.6\%), beta-haemolytic Streptococcus spp. (12.1\%), Bordetella bronchiseptica (12.1\%), nonhaemolytic Streptococcus/ Enterococcus spp. group $(12.1 \%)$, coagulase-positive Staphylococcus spp. (9.5\%), and Pseudomonas spp. (7.8\%) [6]. Similar prevalence was reported by Bonde et al. [13] with nasal swab microbial cultures revealed Gram positive organisms Staphylococci spp. and Streptococci spp. and Gram negative E. coli at Bombay veterinary college, Mumbai. Similar findings were reported Basso et al. [7] who performed culture and isolated bacteria such as Staphylococcus aureus, Klebsiella pneumoniae, E. coli. Furthermore, 17 different bacterial species of Streptococci spp., Enterobacteriaceae and staphylococci spp. were isolated by previous workers [8] from nasal swabs. Other works such as those of Centil et al. [5] revealed the aetiology and diagnosis of bacteria as the causative organisms of respiratory diseases in dogs. These findings were supported well by Charkrabarthi [9] who reported that, Klebsiella pneumoni and, E. coli spp. were the common bacteria in respiratory infectious diseases. Earlier findings of Christina et al [3] also support our work who found heavy growth of beta-haemolytic Streptococci, Saphylococcus and Klebsiella species from the bacterial cultures of the nasal swab. In accordance with our findings, Creighton and Wilkins [14] reported that E. coli, Bordetella bronchiseptica, Klebsiella spp. and Pseudomonas spp. accounted for 58\% of the isolates in respiratory tract secretions. Similar prevalence was reported in the studies of Durgut et al. [16] who demonstrated that all of the pharyngeal and transtracheal aspirates yielded positive results in bacterial culture. Pasteurella spp., Enterobacter spp., E. coli, Klebsiella pneumoniae and Streptococci spp. were isolated [16]. Furthermore, Johnson et al. [22] diagnosed lower respiratory disease in dogs and their findings agree well with Kim Moonsun et al. [23] and reported that bacterial pathogens were isolated from 36 dogs with respiratory signs. Of 36 isolates, $16(44.4 \%)$ were Gram-positive and $20(55.6 \%)$ were Gram-negative. Gram-positive bacteria identified were 18 Staphylococcus spp. (44.5\%), Gram-negative organisms included 8 Bordetella bronchiseptica (22.2\%), 6 E. coli (16.7\%), 4 Pasteurella spp. (11.1\%), one Enterobacter intermedius (2.8\%), and one Oligella ureolytica $(2.8 \%)$ [22]. Similar prevalence was observed by Knotek et al. [24] who examined a total of 40 cases and showed that
16 cases (40\%) were bacterial rhinitis with Staphylococcus spp., and Streptococcus canis on culture. Whereas Lamm et al. [25] reported that Streptococcus spp. are the common opportunistic pathogens that normally reside in the upper respiratory, intestinal, lower urinary and genital tracts. These findings agree well with Maden et al. [26], who examined 25 dogs with respiratory diseases along with 6 healthy controls for clinical and bacteriological findings. Cocci or bacillus or both were isolated from all diseased cases. Earlier studies of Mannering et al. [27] used culture and isolation of the strain typing of 14 Mycoplasma cynos from trachea of six dogs with respiratory disease, from two separate kennels in the United Kingdom. Also, observations made by Priestnall et al. [11] indicted that Streptococcus equi sub spp. zooepidemicus has been linked to cases of acute fatal pneumonia in dogs in several countries.

\section{Conclusion}

Our study revealed respiratory diseases in dogs examined from areas in and around Hyderabad city are by various bacteria viz., E. coli, Klebsiella spp. and mixed infections lead to a milder form of respiratory diseases. Similarly various bacteria viz., E. coli, Klebsiella spp., Streptococci spp. and mixed infections are responsible for moderate form respiratory diseases. In case of severe respiratory diseases, various bacteria viz., E. coli, Klebsiella spp., Streptococcispp., Staphylococci spp. and mixed infection are responsible.

\section{Authors' contributions}

SA carried out the case study and sample analysis. DST participated in scientific discussion, wise counsel and concrete suggestions. YN participated in scientific discussion, coordination, sample collection and analysis. NS participated in scientific discussion, drafted and revised the manuscript. VG participated in scientific discussion, drafted and revised manuscript. All authors read and approved the final manuscript.

\section{Acknowledgements}

Authors are thankful to Sri Venkatewara Veterinary University, Tirupati, Andhra Pradesh, India for providing necessary facilities and fund to carry out the present investigation.

\section{Competing interests}

The authors declare that they have no competing interests.

\section{References}

1. Adaszek L., Gorna, M., Zietek, J., Kutrzuba, J. and Winiarczyk, S. (2009) Bacterial nosocomial infections in dogs and cats. Zycie Weterynaryjne. 84: 805-808.

2. Albini S., Abril, C., Franchini, M., Hussy, D. and Filioussis, G. (2009) Stenotrophomonas maltophilia isolated from the airways of animals with chronic respiratory disease. SAT, Schweizer Archiv fur Tierheilkunde. 151: 7, 323-328.

3. Christina M., VetEnt, G. and Thomas, R. (2010) Respiratory disease outbreak in East Coast working dogs. MAF Investigation and Diagnostic Centre, Upper Hutt; Sandy McLachlan, New Zealand.Veterinary Pathology, Hamilton. 
4. Epstein S. E., Mellema, M. S. and Hopper, K. (2010) Airway microbial culture and susceptibility patterns in dogs and cats with respiratory disease of varying severity. Journal of Veterinary Emergency and Critical Care. 20: 587-594.

5. Centil M., Guthardt, J., Heusinger, A. and Muller, E. (2012) Coughs, colds, hoarseness - infectious diseases of the respiratory tract in dogs. Praktische Tierarzt. 93: 896-903.

6. Angus, J.C., Jang, S.S. and Hirsh, D.C. (1997) Microbiological study of transtracheal aspirates from dogs with suspected lower respiratory tract disease. J. Am. Vet. Med.Assoc. 210: 55-58.

7. Basso P.C., Raiser, A.G., Brun, M.V., Santos, L.R., Muller, D.C.de.M. and Trindade, A.B. (2009) Bronchoalveolar lavage fluid bacterial isolation and sensibility in health and sick dogs. Ciencia Animal Brasileira. 10: 947-954.

8. Bauer, N., Moritz, A. and Weiss, R. (2003) Comparison of bacterial growth in the upper and lower respiratory tract of healthy dogs. Tierarztliche Praxis. Ausga K, Kleintiere/ Heimtiere. 31: 92-98.

9. Charkrabarthi A. (2009) Text book of Clinical Veterinary Medicine. $3^{\text {rd }}$ Edition. pp. 327-372.

10. Davies O., Casamian-Sorrosal, D., Warman, S. and Clarke, C. (2010) Department of Clinical Veterinary Science, University of Bristol, Langford House, Langford, Bristol, Somerset, BS40 5DU, UK. BSAVA 53rd Annual Congress 2010, Scientific Proceedings, Veterinary Programme, Birmingham, UK, 8-11 April- 2010.

11. Priestnall S. L., Erles, K., Brooks, H. W., Cardwell, J. M.. Waller, A. S., Paillot, R., Robinson, C., Darby, A. C., Holden, M. T. G. and Schoniger, S. (2010) Characterization of pneumonia due to Streptococcus equi subsp. zooepidemicus in dogs. Clinical and Vaccine Immunology;. 17: 1790-1796.

12. Attili A. R., Cerquetella, M., Pampurini, F., Laus, F., Spaterna, A. and Cuteri, V. (2012) Association between enrofloxacin and $\mathrm{N}$-acetylcysteine in recurrent bronchopneumopathies in dogs caused by biofilm producer bacteria. Journal of Animal and Veterinary Advances. 11: 462-469.

13. Bonde, A.V., Sherikar, A.A. and Mulbagal, A.N. (1990) Seroprevalence of Bordetella bronchiseptica and canine parainfluenza virus type 2 in dogs in Bombay. Journal of Bombay Veterinary College. 2: 79-82.

14. Creighton, S.R. and Wilkins, R.J. (1974) Bacteriologic and cytologic evaluation of animals with lower respiratory tract disease using transtracheal aspiration biopsy. J. Am. Ani. Hosp. Asso. 10: 227-232.
15. Amrute, P.K., Muley, V.D., Dighe, D.G., Velhankar, R.D. and Keskar, D.V. (2009) Chronic bronchopneumonia in Great Dane pup at Mumbai. Veterinary World. 2:358-359.

16. Durgut, R., Borku, M. K., Ozkok, S., Pekkaya, S., Guzel, M. and Ozkanlar, Y.E. (2003) Kennel cough syndrome of dogs observed in Ankara province. Indian. Vet. J. 8:743-744.

17. Fenwick, B. (2010) An update on infectious canine respiratory disease. Small animal and exotics. Proceedings of the North American Veterinary Conference, Orlando, Florida, USA, 16-20 January 2010. 713-716.

18. Hulas, C. and Hulas, M. (2009) Kennel cough in dogs etiopathogenesis, treatment, prevention. Weterynaria Praktyce. 6: 21-22.

19. Jane, Sykes (2009) Canine Infectious Respiratory Disease Seminar. University of California, Davis.

20. Sehata, G., Wakatsuki, A, Masubuchi, K., Takahashi, T. and Kokubu, T. (2010) Etiological investigation of canine infectious respiratory disease in Japan. Journal of the Japan Veterinary Medical Association. 63: 538-542.

21. Buxton, A., Fraser, B. and Fraser, Gordon (1977) Text book of Animal Microbiology. Blackwell Science Pub. Ltd

22. Johnson, L. R. and Vernau, W. (2011) Bronchoscopic findings in 48 cats with spontaneous lower respiratory tract disease (2002-2009). Journal of Veterinary Internal Medicine. 25(2): 236-243.

23. Kim, Moonsun, Jongtae Jeong, Tae Kang, Yun Young, Min Young, Ju Lee, Lee Myeong, Son DuSik, Geun Won (2004) Antibiotic resistance of bacterial isolates from nasal discharges of dogs with respiratory diseases. Journal of Veterinary Clinics. 21(2): 133-139.

24. Knotek, Z, Fichtel, T., Kohout, P. and Benak, J. (2001) Diseases of the nasal cavity in the dog. Aetiology, symptomatology, diagnostics. Acta Veterinaria Brno.70: 7382.

25. Lamm, C. G., Ferguson, Lehenbauer, T. W. and Love, B. C. (2010) Streptococcal infection in dogs: a retrospective study of 393 cases. Veterinary Pathology. 47: 387-395.

26. Maden, M., Birdane, M. F., Alkan, F., Hadimli, H. H. and Aslan, V. (2000) Clinical, cytologic, bacteriologic and radiographic analysis of respiratory diseases in dogs. Veteriner Bilimleri Dergisi. 16: 43-50.

27. Mannering, S. A., McAuliffe, L., Lawes, J. R., Erles, K. and Brownlie, J. (2009) Strain typing of Mycoplasma cynos isolates from dogs with respiratory disease. Veterinary Microbiology. 135: 292-296. 